\title{
Quantitative phosphoproteomics to unravel the cellular response to chemical stressors with different modes of action
}

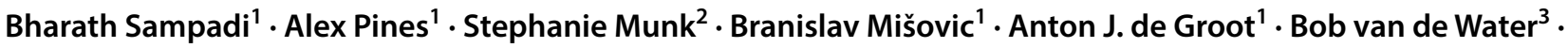 \\ Jesper V. Olsen ${ }^{2} \cdot$ Leon H. F. Mullenders ${ }^{1,4} \cdot$ Harry Vrieling $^{1}(\mathbb{D}$
}

Received: 9 January 2020 / Accepted: 9 March 2020 / Published online: 18 March 2020

(c) The Author(s) 2020

\begin{abstract}
Damage to cellular macromolecules and organelles by chemical exposure evokes activation of various stress response pathways. To what extent different chemical stressors activate common and stressor-specific pathways is largely unknown. Here, we used quantitative phosphoproteomics to compare the signaling events induced by four stressors with different modes of action: the DNA damaging agent: cisplatin (CDDP), the topoisomerase II inhibitor: etoposide (ETO), the prooxidant: diethyl maleate (DEM) and the immunosuppressant: cyclosporine A (CsA) administered at an equitoxic dose to mouse embryonic stem cells. We observed major differences between the stressors in the number and identity of responsive phosphosites and the amplitude of phosphorylation. Kinase motif and pathway analyses indicated that the DNA damage response (DDR) activation by CDDP occurs predominantly through the replication-stress-related Atr kinase, whereas ETO triggers the DDR through Atr as well as the DNA double-strand-break-associated Atm kinase. CsA shares with ETO activation of CK2 kinase. Congruent with their known modes of action, CsA-mediated signaling is related to down-regulation of pathways that control hematopoietic differentiation and immunity, whereas oxidative stress is the most prominent initiator of DEM-modulated stress signaling. This study shows that even at equitoxic doses, different stressors induce distinctive and complex phosphorylation signaling cascades.
\end{abstract}

Keywords Phoshoproteomics $\cdot$ Stress signaling $\cdot$ Cisplatin $\cdot$ Etoposide $\cdot$ Cyclosporine A $\cdot$ Diethyl maleate

\section{Introduction}

Cells are equipped with versatile physiological stress responses to prevent hazardous consequences resulting from exposure to chemical insults of endogenous and exogenous origin. In case these stress responses fall short in their

Bharath Sampadi and Alex Pines wish it to be known that, in their opinion, the first two authors should be regarded as joint first authors.

Accession numbers: All MS raw data and search files are uploaded to the PRIDE repository with the accession number PXD012559.

Electronic supplementary material The online version of this article (https://doi.org/10.1007/s00204-020-02712-7) contains supplementary material, which is available to authorized users.

Harry Vrieling

h.vrieling@lumc.nl

Extended author information available on the last page of the article protective function, cells may die or become derailed with disease development as a potential outcome. Activation of cellular stress responses entails signaling and effector stages with the induction of post-translational modifications (PTM) of specific proteins and directed transcriptional alterations, respectively, as main molecular mechanisms. While stressorinduced changes at the gene expression level have been the focus of numerous studies, the upstream signaling events mediated by PTMs have scarcely been investigated at a proteome-wide level. Among the various types of PTMs that are involved in cellular stress responses, one of the most frequent modifications is the reversible and dynamic phosphorylation of proteins at specific serine $(\mathrm{pS})$, threonine $(\mathrm{pT})$ and tyrosine (pY) residues (Bennetzen et al. 2010; Olsen et al. 2010). Stressor-inflicted DNA damage, alterations in chromatin conformation and changes in DNA metabolism can all activate protein kinases that phosphorylate distinct subsets of proteins (Choudhary and Mann 2010; Polo and Jackson 2011; Warmoes et al. 2013). It has been estimated that almost all proteins in mammalian cells are phosphorylated at 
some point during their expression with over $75 \%$ detected with current mass spectrometry technology (Sharma et al. 2014; Humphrey et al. 2015, 2018). Stable isotope labeling of amino acids in cell culture (SILAC) is one of the most accurate quantification techniques for phosphoproteomics. While SILAC enables small-scale multiplexing of samples, it suffers from a decrease in total phosphopeptide ratio quantifications due to repeated sequencing of phosphopeptide isotope variants (Hogrebe et al. 2018).

In this study, we used SILAC-based phosphoproteomics to investigate to what extent toxic stressors with different modes of action evoke common and stressor-specific signaling responses when administered at equitoxic doses to invitro cultured cells (Pines et al. 2011). We focused on four stressors with distinctive properties and modes of action that do not require bioactivation, i.e. cisplatin (CDDP), etoposide (ETO), diethyl maleate (DEM), and cyclosporine (CsA). CDDP induces intra- and inter-strand DNA cross-links as well as mono adducts that can interfere with transcription and replication (Todd and Lippard 2009; Wang and Lippard 2005). The topoisomerase II inhibitor ETO forms a ternary complex with topoisomerase II and DNA leading to the formation of DNA double-strand breaks (DSBs) in transcribed genes and at replication forks (Deweese and Osheroff 2009; Vesela et al. 2017). Exposure to the pro-oxidant DEM generates a rapid depletion of cellular GSH and as a consequence leads to enhanced levels of reactive oxygen species (ROS) that may induce lipid peroxidation (Tirmenstein et al. 2000; Weber et al. 1990). The immunosuppressive agent CsA is a non-genotoxic carcinogen in humans (Olshan et al. 1994) and mouse (Kesteren et al. 2009) and acts as an inhibitor of the protein phosphatase calcineurin (Leyking et al. 2015; Matsuda and Koyasu 2000). Phosphoproteome analyses allowed us to identify common and stressor-specific phosphorylation signaling pathways for each of the four stressors and provide insights into the nature of the cellular processes that are (in)activated to minimize cellular toxicity by stressors with different modes of action.

\section{Materials and methods}

\section{Cell culture and treatment}

Cell culture and treatment of wild-type B4418 mouse embryonic stem (mES) cells were essentially performed as previously described (Pines et al. 2011). Sub-confluent cultures of $\mathrm{mES}$ cells were exposed to either CDDP $(5 \mu \mathrm{M})$ (Accord, $1 \mathrm{mg} / \mathrm{ml})$, CsA $(20 \mu \mathrm{M})$ (Sigma, Catalog No. 30024-25 mg), DEM $(150 \mu \mathrm{M})$ (Sigma, Catalog No. D97703-100G) or ETO $(0.5 \mu \mathrm{M})$ (Sigma, Catalog No. E1383-25 mg) by adding the drug directly to the culture medium and cells were incubated for different periods after administration $(2,4,6$ and
$24 \mathrm{~h})$. To inhibit Atm and Atr functions, cells were treated with the Atm inhibitor Ku-55933 (10 $\mu \mathrm{M})$ (Selleckchem, Catalog No. S1092) and the Atr inhibitor VE-821 (1 $\mu \mathrm{M})$ (Selleckchem, Catalog No. S8007), respectively. Cell culture media was prepared by mixing $55 \mathrm{ml}$ dialyzed FBS (Thermo Scientific Catalog No. 88440), 5.5 ml Glutamax (Life Technologies, Catalog No. 35050-038), 5.5 ml PenStrep (Life Technologies, Catalog No. 15140-122), $1.25 \mathrm{ml}$ $\beta$-mercaptoethanol (Gibco, Catalog No. 31350010) and $55 \mu$ l leukemia inhibitory factor (LIF) (Millipore, Catalog No. ESG1107) to $500 \mathrm{ml}$ DMEM media minus L-lysine and L-arginine (Thermo scientific, Catalog No. 89985). An appropriate amount of medium was prepared for labeling cells using $10 \mathrm{mg}$ arginine, $20 \mathrm{mg}$ lysine and $20 \mathrm{mg}$ proline for $100 \mathrm{ml}$ medium. Light SILAC: L-arginine (Arg 0) (Cambridge Isotope Laboratories Inc, Catalog No. ULM-8347) and L-lysine:2HCl (Lys 0) (Cambridge Isotope Laboratories Inc, Catalog No. ULM-8766), Medium SILAC: L-arginine$\mathrm{U}_{-}{ }^{13} \mathrm{C}_{6}$ (Arg6) (Cambridge Isotope Laboratories Inc, Cata$\log$ No. CLM-2265-H) and L-lysine-U-4,4,5,5,-D4 (Lys 4) (Cambridge Isotope Laboratories Inc, Catalog No. DLM2640) and Heavy SILAC: L-arginine- $\mathrm{U}_{-}{ }^{13} \mathrm{C}_{6}, 99 \%$; $\mathrm{U}_{-}{ }^{15} \mathrm{~N}_{4}$, 99\% (Arg 10) (Cambridge Isotope Laboratories Inc, Catalog No. CNLM-539) and L-lysine-U- ${ }_{-}^{13} \mathrm{C}_{6}, 99 \%$; U- ${ }^{15} \mathrm{~N}_{2}, 99 \%$ (Lys 8) (Cambridge Isotope Laboratories Inc, Catalog No. CNLM-291). Furthermore, L-proline (Cambridge Isotope Laboratories Inc, Catalog No. ULM-8333) was added to all SILAC media to prevent arginine to proline conversion, which sometimes makes interpretation of MS data more difficult. Cells were cultured in an isotopically labeled medium for 6-7 cycles before performing experiments for MS analysis. During passages, the medium was decanted, cells were washed with PBS (Dulbecco's PBS without calcium, magnesium, and phenol red $500 \mathrm{ml}$; Life Technologies, Catalog No. 14190086) and trypsinized using TrypLE (100 ml; Life Technologies, Catalog No. 12604-013).

\section{Phosphoproteomic sample preparation}

Protein sample collection, phosphopeptide enrichment, and cleanup were performed according to previously published procedures (Pines et al. 2011). Briefly, cells were collected after $4 \mathrm{~h}$ of drug treatment by trypsinization and cell pellets were lysed for $30 \mathrm{~min}$ in lysis buffer [ $8 \mathrm{M}$ urea, $50 \mathrm{mM}$ Tris ( $\mathrm{pH} 8.1$ ), $75 \mathrm{mM} \mathrm{NaCl}, 1 \mathrm{mM} \mathrm{MgCl} 2,500$ Units benzonase (Novagen, Catalog No. 71205-3), 1 tablet complete mini protease inhibitor, EDTA-free (Roche, Catalog No. 11836170001), $100 \mu$ l Phosphatase Inhibitor Cocktail 3 (RT 1 h before use; Sigma, Catalog No. P0044-5ML) and $100 \mu \mathrm{l}$ Phosphatase Inhibitor Cocktail 2 (Sigma, Catalog No. P5726-5ML)]. Samples were then centrifuged (13,000 rpm $15 \mathrm{~min}$ ) to remove the cell debris. Protein concentrations were estimated (Qubit Protein Assay kit; Invitrogen, Catalog 
No. Q33212) and $10 \mathrm{mg}$ of proteins per sample was taken for protein digestion. After reduction $(2.5 \mathrm{mM}$ dithiothreitol (DTT) for $25 \mathrm{~min}$ at $60{ }^{\circ} \mathrm{C}$ ), alkylation $[7 \mathrm{mM}$ iodoacetamide for $15 \mathrm{~min}$ at room temperature (RT) in dark] and quenching (2.5 mM DTT for $15 \mathrm{~min}$ at RT), samples were diluted eightfold with $25 \mathrm{mM}$ Tris $(\mathrm{pH} 8.1)-1 \mathrm{mM} \mathrm{CaCl}_{2}$. Proteins were digested with $100 \mu \mathrm{g}$ trypsin (sequencing grade $100 \mu \mathrm{g}$; Promega, Catalog No. V5111) for $15 \mathrm{~h}$ at $37{ }^{\circ} \mathrm{C}$ and the reaction was stopped by adding trifluoroacetic acid (TFA) to a final concentration of $0.4 \%$. Following centrifugation (3200 rpm for $5 \mathrm{~min}$ ), supernatants containing tryptic peptides were loaded onto $\mathrm{tC}_{18}$ cartridges (Sep-Pak Vac $1 \mathrm{cc}$ $100 \mathrm{mg}$; Waters, Catalog No. WAT036820). Peptides were desalted $(0.1 \%$ acetic acid), eluted $[0.1 \%$ acetic acid (ACA) and $30 \%$ acetonitrile (ACN)], lyophilized and fractionated on a 9.4 by $200-\mathrm{mm} 5 \mu \mathrm{m}$ particle polysulfoethyl, a strong cation exchange (SCX) column (PolyLC) at $1 \mathrm{ml} / \mathrm{min}$ using a 70 -min gradient from 0 to $75 \mathrm{mM} \mathrm{KCl}$, with $350 \mathrm{mM} \mathrm{KCl}$ for $38 \mathrm{~min}$ in $5 \mathrm{mM} \mathrm{KH}_{2} \mathrm{PO}_{4}(\mathrm{pH} 2.65)$ and $30 \%$ acetonitrile. Initially, 18 fractions were collected and during desalting, the last 8 fractions were combined into 4 leading to a total of 14 fractions which were then lyophilized. Each of these 14 fractions were then dissolved in buffer A $(300 \mathrm{mg} / \mathrm{ml}$ lactic acid, $80 \%$ ACN, $0.1 \%$ TFA) and loaded on to titanium dioxide $\left(\mathrm{TiO}_{2}\right)$ columns (TopTip 1-10 $\mu$; Glygen Corporation, Catalog No. TT1TIO96) prewashed with elution buffer (15 $\left.\mathrm{mM} \mathrm{NH}_{4} \mathrm{OH}, \mathrm{pH} 10.5\right)$, equilibration buffer (0.1\% TFA) and buffer A. Samples were then washed with buffer A and B [ $80 \%$ ACN (v/v), 0.1\% TFA (v/v)]. Phosphopeptides were eluted from the columns with elution buffer and collected in Eppendorf tubes with equal volumes of 2\% TFA. Phosphopeptides were subsequently loaded onto Stage Tip $\mathrm{C}_{18}$ column (20 $\mu \mathrm{l}$; Proxeon, Catalog No. SP201) equilibrated with methanol, buffer B and $0.1 \%$ TFA. Next, they were desalted ( $0.1 \%$ TFA), eluted (buffer B) and lyophilized and stored at $-80^{\circ} \mathrm{C}$.

\section{High-performance liquid chromatography (HPLC) and mass spectrometry (MS) measurements}

HPLC and MS measurements were performed as described below. Phosphopeptides were resuspended in 5\% acetonitrile $(\mathrm{ACN})$ in $0.1 \%$ trifluoroacetic acid for downstream MS analysis. All enriched samples were analyzed by online LC-MS/MS on an EASY-nLC system (Thermo Scientific, Odense, Denmark, Catalog No. LC120) interfaced with a Q-Exactive orbitrap mass spectrometer (Thermo Electron, Bremen, Germany, Catalog No. IQLAAEGAAPFALGMAZR) through a nano-electrospray ion source. All peptides were auto-sampled and separated on a $15 \mathrm{~cm}$ column ( $75 \mu \mathrm{m}$ internal diameter) packed in-house with $3 \mu \mathrm{m} \mathrm{C} 18$ beads (Reprosil-AQ Pur, Dr. Maisch, Germany, Catalog No. r13. aq). Peptides were separated over $80 \mathrm{~min}$ by a linear gradient from 8 to $60 \%$ of acetonitrile (ACN) in $0.5 \%$ acetic at a flow rate of $500 \mathrm{nl} / \mathrm{min}$ till $10 \% \mathrm{ACN}$, then $250 \mathrm{nl} / \mathrm{min}$ up to $50 \%$ $\mathrm{ACN}$ and then $500 \mathrm{nl} / \mathrm{min}$ for the remaining gradient. Spray voltage was $2 \mathrm{kV}$, S-lens RF level at $50 \%$, heated capillary at $275{ }^{\circ} \mathrm{C}$, no sheath or auxiliary gas flow. MS was performed in a data-dependent acquisition mode where the 12 most intense, multiply charged peaks were chosen for fragmentation after acquiring each full spectrum. Dynamic exclusion was used set to $30 \mathrm{~s}$ to avoid picking peaks more than once. Full scans were acquired at a mass range of $300-1750 \mathrm{~m} / \mathrm{z}$ with a resolution of 70,000 at $\mathrm{m} / z 200$, with target $3 \times 10^{6}$ based on predictive AGC from the previous full scan, with a maximum fill time of $30 \mathrm{~ms}$. Fragmentation was performed using Higher energy Collisional Dissociation (HCD) with a normalized HCD collision energy $25 \%$ and acquired with the target set to $3 \times 10^{6}$, with max injection time of $120 \mathrm{~ms}$ at 35,000 resolution with an isolation window of $2 \mathrm{~m} / \mathrm{z}$.

\section{MS data analysis}

The raw MS data were processed in MaxQuant (version 1.5.7.4) (FDR $<0.01$ at the protein, peptides, and modifications levels) using the default settings with the following minor changes: SILAC triplet was activated (light $=$ default; medium = Lys4; Arg6; heavy = Lys8; Arg10). Acetylation (Protein N-term), oxidation (M) and phosphorylation (STY) were selected as variable modifications and carbamidomethylation (C) was selected as a fixed modification. A minimum peptide length of six amino acids was set and "match between runs" (MBR) was enabled with the default value. A reverse sequence database was used to identify proteins and peptides by the inbuilt Andromeda search engine using the Mouse Uniprot FASTA database (November 2016). "ReQuantify" (REQ) was switched on. Further downstream analyses were performed using Perseus (version 1.5.5.3), Microsoft Excel (2016), R and Graphpad Prism (version 7); protein annotations were extracted from Gene Ontology (GO) and kinase-substrate relations were based on Phosphosite Plus database (October 2019) (phosphosite.org).

Normalized SILAC ratios from the "phospho(STY)sites. txt" file were first loaded in Perseus, $\log _{2}$ transformed and the phosphosites were expanded into singly, doubly and multiply phosphorylated sites. Next, the reverse hits and contaminants were filtered out and the dataset was filtered to include at least one valid value. We also removed "normalized H/M" ratios from the dataset which resulted in the identification of 15,898 phosphosites in total. For the hierarchical clustering of all the 15,898 phosphosites, we $Z$-scored the data. The $\log _{2}$ values of the replicates per stressor were then median averaged and used for analyses presented. For motif analysis presented in Fig. 3, up- and down-regulated phosphosites were identified by applying a 1.5 -fold change cut-off and the numbers are indicated in a table below the 
figure. For pairwise comparison of the phosphoproteome of the other stressors with that of cisplatin, we compared all six replicates of CDDP to two replicates of each of the other stressors by performing a two-sample Student's $t$-test with a permutation-based FDR cut-off set at 0.05 . Analysis of variance (ANOVA) was performed on the entire dataset consisting of 15,898 phosphosites with a permutation-based FDR cut-off set at 0.05 .

\section{Pathway and motif analyses}

For pathway analysis, we used a combination of two criteria to identify stressor-responsive phosphosites being either significantly responding (ANOVA; FDR $<0.05$ ) or passing a fold-change threshold $(>1.5)$ totaling 7883 phosphosites. These sites were subsequently analyzed using the "Phosphorylation Analysis" module of Ingenuity Pathway Analysis (IPA, Qiagen) software. Significantly responsive pathways were represented using the "Canonical Pathways" module with $p$-value, Benjamini-Hochberg corrected $p$-value and $Z$-score cut-offs set at $0.01,0.01$ and 2 , respectively. To identify key kinases and phosphatases upstream of the phosphorylation events, we used the "upstream analysis" module of IPA with $p$-value and Z-score cut-offs set at 0.05 and 2, respectively.

Motif analysis was performed using the IceLogo tool (Colaert et al. 2009) using the sequences of the total phosphosites from either individual stressors or the entire phosphoproteome dataset as background depending on the analyses performed. Results were visualized as percentage difference (\% difference) and a $p$-value of 0.05 was set as the cut-off.

\section{Western blot analysis}

Western blot analysis of total cell extracts was performed as described previously (Pines et al. 2011) and protein bands were analyzed and visualized with the Odyssey infrared imaging system (LI-COR) using secondary antibodies labeled with visible fluorophores (LI-COR, IRDye ${ }^{\circledR}$ 800CW Goat anti-Mouse IgG $(\mathrm{H}+\mathrm{L})$, Catalog No. 92632210; IRDye ${ }^{\circledR} 800 \mathrm{CW}$ Goat anti-Rabbit IgG $(\mathrm{H}+\mathrm{L})$, Catalog No. 926-32211; IRDye ${ }^{\circledR}$ 680RD Goat anti-Mouse $\operatorname{IgG}(\mathrm{H}+\mathrm{L})$, Catalog No. 926-68070; and IRDye ${ }^{\circledR}$ 680RD Goat anti-Rabbit IgG $(\mathrm{H}+\mathrm{L})$, Catalog No. 926-68071). The primary antibodies employed were mouse anti-phospho-Histone H2AX (Ser139) antibody, clone JBW301 (Millipore, Catalog No. 05-636), rabbit anti-H2B (Millipore, Catalog No. 07-371), mouse anti-pS1981 ATM (10H11.E12) (Cell Signaling Technology, Catalog No. 4526), rabbit anti-ATM (D2E2) (Cell Signaling Technology, Catalog No. 2873), and rabbit anti-pS15 p53 (Cell Signaling Technology, Catalog No. 9284).

\section{Flow cytometry analysis}

For cell cycle analysis, samples were either treated with a stressor for $0.5,2,4$, or $8 \mathrm{~h}$ or mock-treated after which 5-ethynyl-2'-deoxyuridine (EdU, $40 \mu \mathrm{M}$ in DMSO) was added to the medium. Cells were collected $30 \mathrm{~min}$ after the addition of EdU label and stained using the Click-iT ${ }^{\circledR}$ EdU Alexa Fluor ${ }^{\circledR} 488$ Flow Cytometry Assay Kit (Invitrogen, Catalog No. C-10425) according to the manufacturer's protocol. In brief, $6 \times 10^{5}$ cells were seeded in p60 plates 1 day before the experiment. Cells were treated with stressors and $40 \mu \mathrm{M}$ EdU was added to the medium 30 min before the end of the exposure. Cells were trypsinized, washed once with $1 \mathrm{ml}$ of $1 \%$ BSA in PBS, pelleted by centrifugation. Cell pellets were dislodged using $50 \mu$ of Click-iT ${ }^{\circledR}$ fixative (component D), mixed thoroughly and incubated for $15 \mathrm{~min}$ at room temperature, protected from light. Cells were next washed with $1 \mathrm{ml}$ of $1 \% \mathrm{BSA}$ in PBS and pelleted. Cell pellets were dislodged and resuspended in $50 \mu \mathrm{l}$ of $1 \mathrm{x}$ Click-iT ${ }^{\circledR}$ saponin-based permeabilization and wash reagent (prepared by adding 1 volume of component $\mathrm{E}$ to 9 volumes of $1 \%$ BSA in PBS, pH 7.1-7.4), mixed well and incubated for 15 min. Click-iT ${ }^{\circledR}$ reaction cocktail was prepared as follows: For each sample, $219 \mu \mathrm{lBS}, 5 \mu \mathrm{CuSO}_{4}$ (component F), $1.25 \mu$ Fluorescent dye azide (prepared by adding $130 \mu \mathrm{l}$ of DMSO to component B) and $25 \mu \mathrm{l}$ reaction buffer additive $(10 \times$ stock was prepared by adding $2 \mathrm{ml}$ deionized water to component G: Click-iT ${ }^{\circledR}$ EdU buffer additive) were mixed. The Click-i ${ }^{\circledR}$ reaction cocktail was then added to the cell suspension.

\section{Cell viability and apoptosis/necrosis assays}

Mouse ES cells were treated with either vehicle or stressor for 24 h; ATP Lite (Perkin Elmer, Catalog No. 6016943) was subsequently used for the assessment of cell viability according to the manufacturer's instructions. In brief, cells were lysed by adding $50 \mu \mathrm{l}$ mammalian cell lysis solution per $100 \mu \mathrm{l}$ cell suspension and shaken in an orbital shaker for $5 \mathrm{~min}$ at $700 \mathrm{rpm}$. Next, $50 \mu \mathrm{l}$ substrate solution was added to each well and the microplate was put for $5 \mathrm{~min}$ in an orbital shaker at $700 \mathrm{rpm}$. After the adaptation of the plate for $10 \mathrm{~min}$ to the dark, luminescence was measured.

Apoptotic cells were identified by Annexin V staining using the Alexa Fluor ${ }^{\circledR} 488$ annexin V Dead Cell Apoptosis Kit (Invitrogen, Catalog No. V13241) with RNAse treatment as described previously (Pines et al. 2011). In brief, $6 \times 10^{5}$ cells were seeded in p60 plates 1 day before treatment with stressors. After desired incubation times, the medium was collected, cells were washed with PBS and trypsinized. The reaction was stopped by adding the collected medium to the trypsinized cells. Cells were then centrifuged and washed with PBS. Cells were pelleted, PBS discarded and 
resuspended in $250 \mu \mathrm{l} 1 \mathrm{x}$ annexin-binding buffer (diluted from $5 \mathrm{x}$ annexin-binding buffer (component $\mathrm{C}$ ): $50 \mathrm{mM}$ HEPES, $700 \mathrm{mM} \mathrm{NaCl}, 12.5 \mathrm{mM} \mathrm{CaCl}_{2}$, pH 7.4, with deionized water). Next, $60 \mu \mathrm{l}$ staining solution ( $5 \mu \mathrm{l}$ Alexa Fluor ${ }^{\circledR} 488$ annexin V (component A: solution in $25 \mathrm{mM}$ HEPES, $140 \mathrm{mM} \mathrm{NaCl}, 1 \mathrm{mM}$ EDTA, pH 7.4, 0.1\% bovine serum albumin (BSA)) and $5 \mu \mathrm{l} 20 \mu \mathrm{g} / \mathrm{ml}$ propidium iodide in $50 \mu \mathrm{l} 1 \mathrm{x}$ annexin-binding buffer (component B: $1 \mathrm{mg} / \mathrm{ml}$ $(1.5 \mathrm{mM})$ solution in deionized water) was added to $50 \mu \mathrm{l}$ cell suspension of each sample and incubated at room temperature for $15 \mathrm{~min}$. Cells were centrifuged for $5 \mathrm{~min}$ at $500 \mathrm{~g}$ and resuspended in cold $100 \mu \mathrm{l}$ annexin-binding buffer. Next, $100 \mu \mathrm{l} 2 \%$ formaldehyde in annexin-binding buffer was added and incubated for $10 \mathrm{~min}$ on ice. Cells were centrifuged for $5 \mathrm{~min}$ at $500 \mathrm{~g}$ and washed with $200 \mu \mathrm{l} 1 \% \mathrm{BSA}$ in PBS. Cells were resuspended in $100 \mu 11 \%$ BSA in PBS and $4 \mu \mathrm{l}$ of RNAse $20 \mathrm{mg} / \mathrm{ml}$ and incubated for $15 \mathrm{~min}$ at $37^{\circ} \mathrm{C}$. Subsequently, $10 \mu \mathrm{l}$ of the cell suspension was transferred to well in 96-well plate with $120 \mu \mathrm{l}$ 1\% BSA in PBS in each well and analyzed using a Guava FACS system. The stained cells were analyzed by flow cytometry, measuring the fluorescence emission at $530 \mathrm{~nm}$ and $575 \mathrm{~nm}$ (or equivalent) using $488 \mathrm{~nm}$ excitation. Flow cytometry results were confirmed by visual inspection with a fluorescence microscope using filters appropriate for fluorescein (FITC) and tetramethylrhodamine (TRITC) or Texas Red ${ }^{\circledR}$ dye.

\section{Results}

\section{Stressor-induced cellular responses}

Mouse ES cells are untransformed, can divide indefinitely and have intact DNA damage response pathways and represent an excellent cell system to compare stress responses by chemical agents with different modes of action. We determined the viability of mES cells after $24 \mathrm{~h}$ of exposure to the DNA damaging agent CDDP, the topoisomerase inhibitor ETO, the pro-oxidant DEM and the immunosuppressant CsA (Fig. 1a). Inter-stressor comparisons were subsequently made at the dose for each stressor that resulted in approximately 50\% reduction of viability (IC50) upon $24 \mathrm{~h}$ of treatment as determined by the ATPlite assay. Treatment of mES cells with CDDP and ETO at this equitoxic dose led to an inhibition of DNA synthesis as indicated by a gradual reduction of the EdU incorporation over time (Fig. 1b). Also following CsA exposure, a reduction in EdU incorporation was observed, although less pronounced and delayed when compared to CDDP and ETO treatments. In contrast, EdU incorporation was virtually unaffected by DEM treatment.

\section{Phosphoproteomics}

To identify activation of common and stressor-specific signaling pathways, we performed SILAC-based global phosphoproteomics following exposure to each of the four stressors at the respective IC50 concentration. Cells were grown in SILAC media containing 'light', 'medium' or 'heavy' isotopologues of the amino acids arginine ( $\operatorname{Arg}^{0}$, $\mathrm{Arg}^{6}, \mathrm{Arg}^{10}$ ) and lysine $\left(\mathrm{Lys}^{0}, \mathrm{Lys}^{4}, \mathrm{Lys}^{8}\right)$ (Supplementary Fig. S1A). In contrast to ion channel and receptor activation-mediated phosphorylation signaling that occurs very early within seconds to minutes time scale (Francavilla et al. 2013; Batth et al. 2018), stress-related phosphorylation signaling cascades are early and intermediate events (Purvis and Lahav 2013). Therefore, we chose $4 \mathrm{~h}$ as the time point to profile the phosphoproteome after exposure to each of the four stressors since we aimed to identify common and shared biological pathways. Following trypsinization and cell lysis, SILAC-labeled proteins were mixed in equal ratios and proteolyzed using trypsin. Peptides were first separated into 14 fractions based on their charge using strong cation exchange (SCX) chromatography. Each of the 14 fractions was next enriched for phosphopeptides using $\mathrm{TiO}_{2}$ chromatography followed by nano-flow liquid chromatography-tandem mass spectrometry (LC-MS/MS) analysis, quantified using MaxQuant (Tyanova et al. 2016a) and subjected to downstream analysis using Perseus (Supplementary Fig. S1B) (Tyanova et al. 2016b).

We performed, in biological duplicates, three separate experiments in each of which Light- and Heavy-SILAC cells were mock treated and CDDP treated, respectively. The Medium-SILAC cells in each of these experiments were treated with either ETO, CsA, or DEM (Supplementary Fig. 1A). As a result, we obtained six phosphoproteomes each for control and CDDP-treated cells, and two phosphoproteomes each for ETO-, DEM- and CsA-treated cells. This experimental design had three major advantages. First, the inclusion of mock-treated controls in all experiments $(6 \times \mathrm{L}$ channels) allowed robust SILAC ratio estimations for all stressors over untreated controls. Next, the inclusion of CDDP-treated cells in all experiments $(6 \times \mathrm{H}$ channels) served as an internal control and increased the statistical power of the dataset enabling the application of false discovery rate (FDR) correction of 0.05 for all the statistical tests. Finally, the inclusion of CDDP-treated cells in all experiments enabled us to perform a comparison of the relative phosphoproteome changes observed after CDDP treatment versus those induced by either ETO, CsA or DEM. We quantified in total 15,898 phosphosites (on 4086 proteins) of which 6667 phosphosites were quantified in all 4 stressors. The phosphoproteome coverage distribution plot (Supplementary Fig. S1C) showed, except for DEM, similar quantification depths for all stressors quantifying 15,884 
Fig. 1 Cellular responses induced by the chemical stressors. a mES cells were treated with CDDP, CsA, DEM and ETO and viability was assayed at $24 \mathrm{~h}$ after initiation of the treatment by ATP lite at indicated doses. IC50 values are indicated as dark blue dots. b Effect of stressors on DNA replication was determined by time course flow cytometric analysis of EdU incorporation. Statistics: one-way ANOVA test between control cells and other indicated treatments $(* * * * p$-value $<0.001 ; * *$-value $=0.0045$; n.s. not significant) (colour figure online)

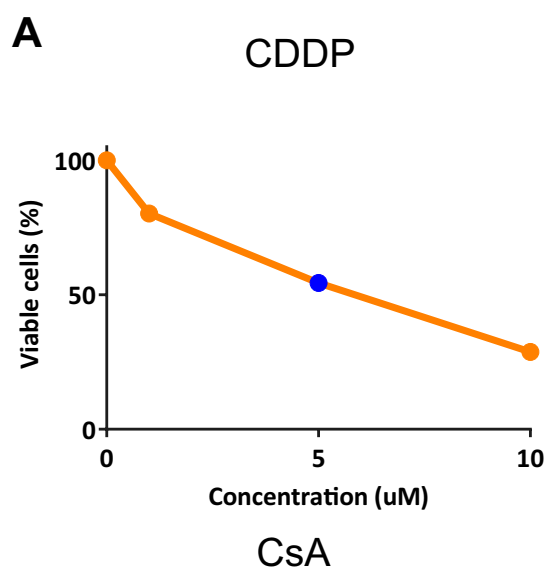

B
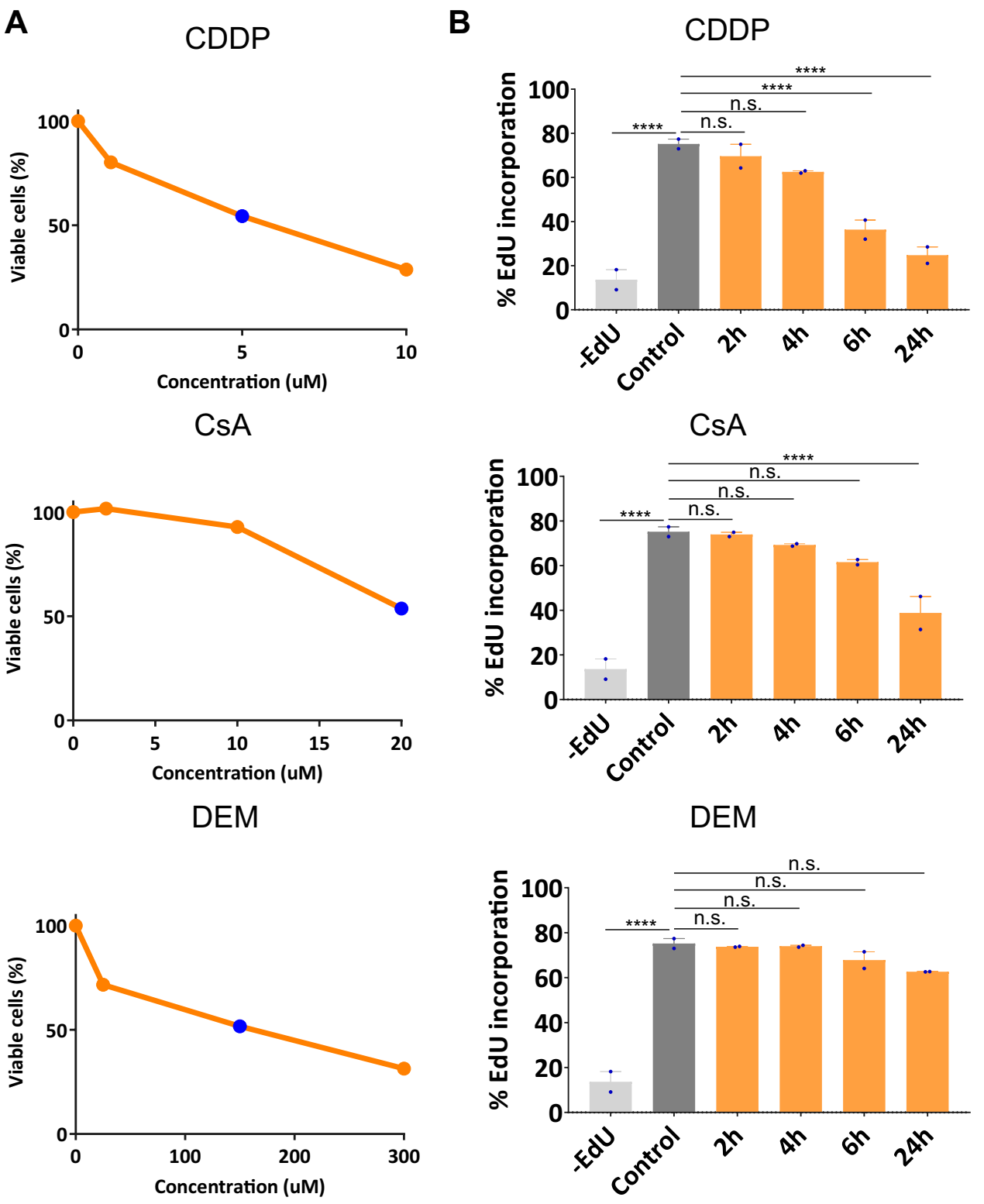

ETO

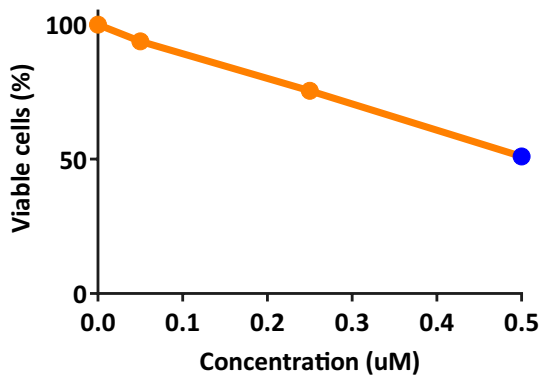

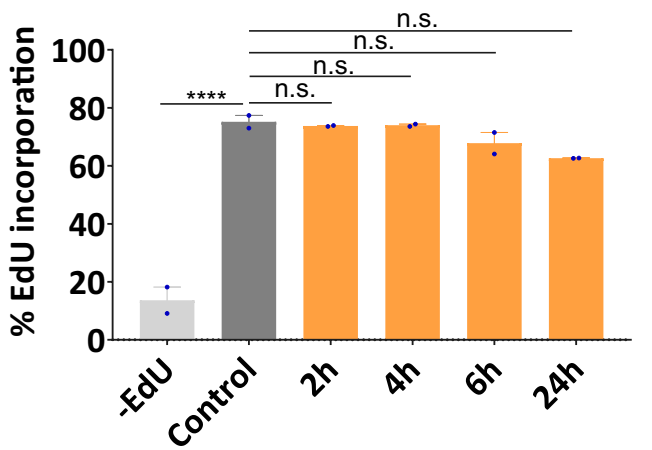

ETO

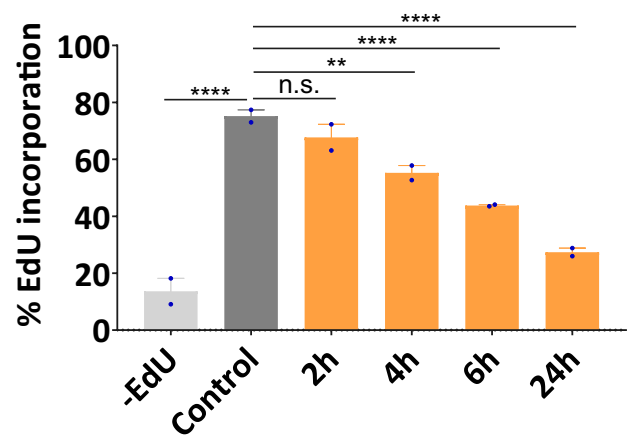

sites in CDDP-treated, 12,684 sites in CsA-treated, 12,554 sites in ETO-treated and 8324 sites in DEM-treated cells. The experiments showed good reproducibility between biological replicates (Supplementary Fig. S2). The overlap of the global SILAC phosphosite ratio quantifications between two biological replicates was around $65 \%$ and is 
on-par with previously published studies (Hogrebe et al. 2018; Piersma et al. 2015). The distribution of phosphorylated amino acids revealed that the phosphoproteome contained 13,366 (84\%) pS, $2425(15.3 \%)$ pT and $107(0.7 \%)$ pY, which is similar to other studies (Olsen et al. 2010; Sharma et al. 2014; Mazouzi et al. 2016). The majority of the phosphosites were localized to a single amino acid [12,746 (80.2\%)] with high confidence, Class I sites (phosphopeptide localization probability $\geq 0.75$ ). Of the remainder, $2986(18.8 \%)$ and $166(1 \%)$ phosphosites represented
Class II $(0.75>x \geq 0.5)$ and Class III $(0.5>x \geq 0.25)$ sites, respectively. Similarly, the distribution of phosphorylation multiplicity revealed that 11,794 (74.2\%), 3718 (23.4\%) and 386 (2.4\%) phosphosites were phosphorylated at single, double or multiple sites, respectively.

Unsupervised clustering of all 15,898 phosphosites resulted in clear segregation of the stressors (Fig. 2a) with the phosphorylation response after ETO being the most divergent. To compare the phosphorylation responses of the various stressors, we applied a threshold filter of
Fig. 2 Identification of stressorspecific and stressor-shared differential phosphorylation events. a Unsupervised clustering of quantified phosphosites after $z$ scoring. b Heatmap of 37 responsive phosphosites ( $>1.5$-fold change) shared by all 4 stressors of which 31 phosphosites responded in the same direction for all 4 stressors
A

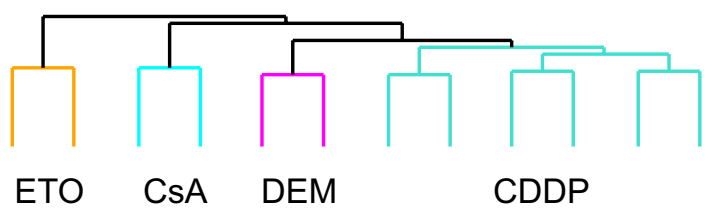

B

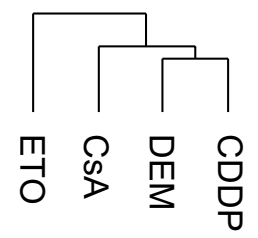

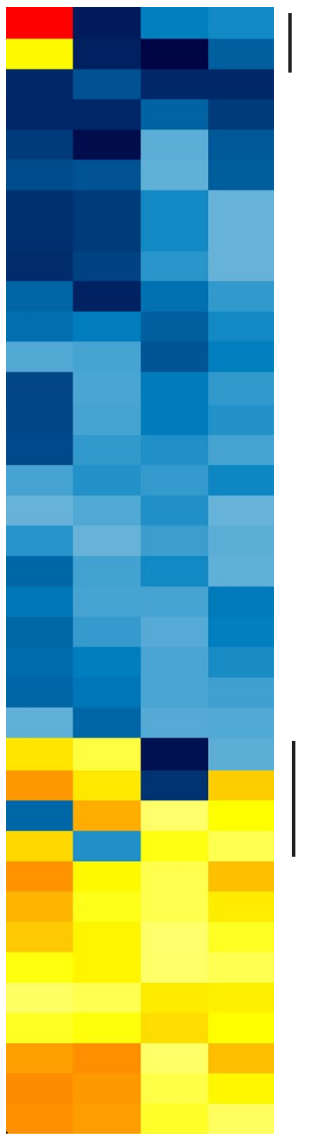

| Divergently regulated

Divergently regulated

Mki67 (S_2425)

-Def8 (S_449)

Coggbp1 (S_163)

Rsf1 (S 350)

Pou2f1 (S_8)

Trappc12 (S_234)

[Cct3 (S_458)

Tssc4 (S_316)

Zc3h3 (S 118)

[Wbscr22 (S_219)

Rbbp7 (S 3) $\log 2$ ratio

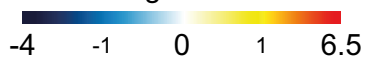


A

Up-regulated phosphosites

CDDP
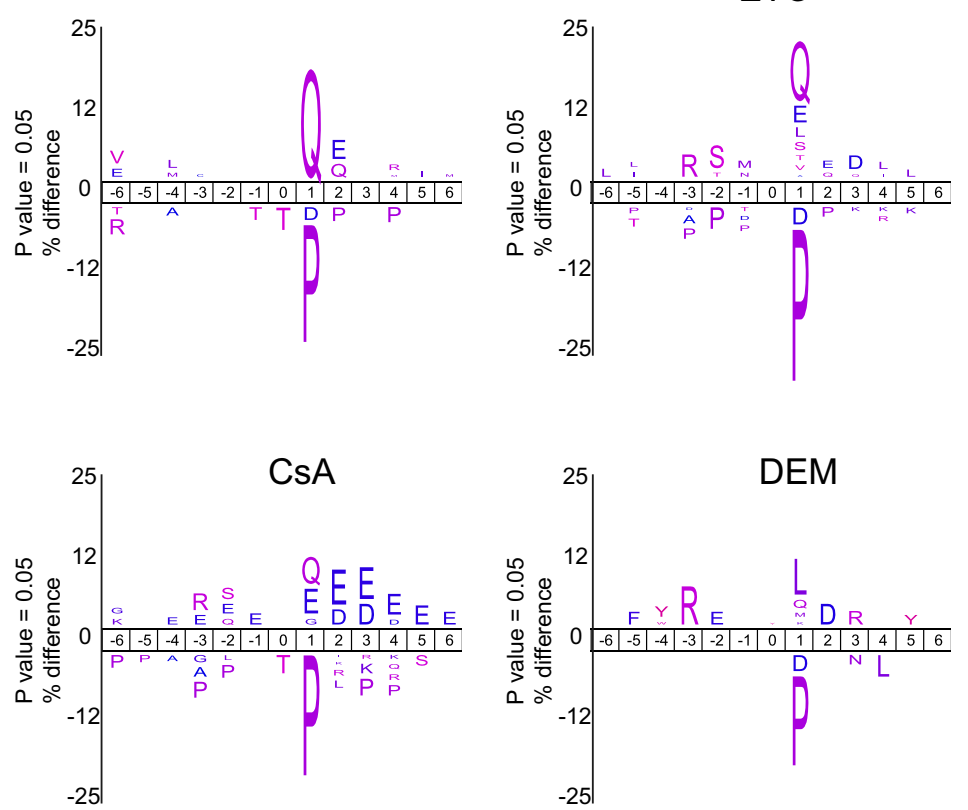

B

Down-regulated phosphosites
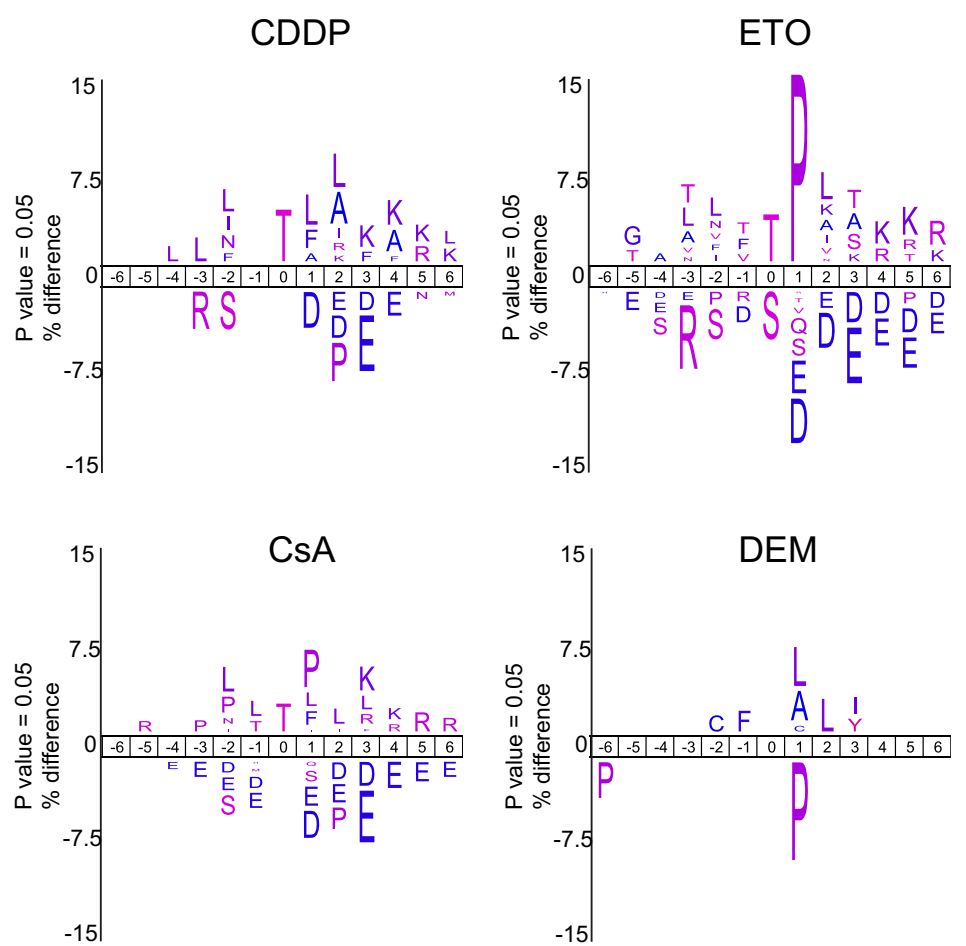

\begin{tabular}{|l|r|r|r|r|r|r|r|}
\hline Stressor & up-reg sites & $\%$ up & down-reg sites & \% down & Total responsive & \% responsive & Total quantified \\
\hline CDDP & 708 & 4.46 & 1131 & 7.12 & 1839 & 11.58 & 15884 \\
\hline ETO & 1473 & 11.73 & 1988 & 15.84 & 3461 & 27.57 & 12554 \\
\hline CSA & 1039 & 8.19 & 1981 & 15.62 & 3020 & 23.81 & 12684 \\
\hline DEM & 327 & 3.93 & 278 & 3.34 & 605 & 7.27 & 8324 \\
\hline
\end{tabular}


4Fig. 3 Motif analyses of differentially regulated phosphosites. Sequence motifs analyses and visualization were performed using the IceLogo tool. The total number of phosphosites used to enrich for motifs are indicated per stressor. For each stressor, the sequences of all quantified phosphosites were used as a statistical background. A $p$-value cut-off of 0.05 was applied. The phosphorylated amino acid is located at position 0. a Motifs enriched for the indicated stressors among the up-regulated phosphosites. b Motifs enriched for the indicated stressors among the down-regulated phosphosites. Table inlet displays an overview of the responsive phosphosites

$1.5 \mathrm{FC}$ to the averaged data, resulting in 6386 phosphosites (40\% of the total sites) that responded to at least 1 of the stressors. We separated these phosphosites based on their direction of response, which resulted in 2677 up-regulated and 3944 down-regulated phosphosites. We found only 37 phosphosites to be commonly responding to all four stressors (Fig. 2b). While 25 of these 37 phosphosites have been reported previously, only one, i.e. pT210 of polo-like kinase $1(P l k l)$ has been described as a regulatory phosphosite. T210 residue is an activation site for $P l k l$ and its dephosphorylation is associated with the installment of a cell cycle arrest (Bruinsma et al. 2017). Additionally, we filtered for phosphosites that were quantified in all 12 experiments $(6 \times$ reps of CDDP and $2 \times$ reps for each CsA, ETO and DEM). Heatmap visualizations of the global response (Supplementary Fig. S3) and of the top50 upregulated phosphosites (Supplementary Fig. S4) display distinct phosphorylation responses for the different stressors.

\section{Protein kinase motif analyses}

To identify upstream protein kinases and phosphatases that are responsible for the global (de)phosphorylation events, we performed motif analysis on the identified stressor-induced phosphosites by applying a threshold filter (1.5-fold change) (Fig. 3). Motif analysis on three biological replicates of CDDP revealed reproducible enrichment of a highly similar kinase motif that was distinctly different from the motifs observed after ETO, CsA, and DEM (Supplementary Fig. S5). CDDP enriched only for the (S/T)Q motif, a consensus motif for the three DDR kinases-Atm, Atr, and Prkdc, whereas ETO and CsA enriched apart from the (S/T)Q motif for an acidic residue at +3 position representing a specificity determinant for Csnk2al (casein kinase II or CK2) kinase (Bian et al. 2013). After CDDP, 19\% (136 out of 708) of the upregulated phosphosites were at (S/T)Q sites compared to 12\% (180 out of 1473 sites) after ETO, 7\% (76 out of 1039 sites) after CsA and 4.5\% (15 out of 327 sites) after DEM with the highest phosphorylation amplitudes observed after ETO (Supplementary Fig. S6). Phosphorylated (S/T)Q sites after CsA largely overlapped with those after CDDP and ETO with only three sites being exclusive for CsA. Remarkably, only a few of the identified (S/T)Q sites after CsA (6 out of 76 sites; $7.9 \%$ ) were on proteins that have been implicated in the DDR in contrast to many more phosphosites following CDDP (40 out of 136 sites, 29.4\%) and ETO (39 out of 180 sites, $21.6 \%$ ) treatments. Analyses of the relative phosphoproteomes of ETO after comparison with CDDP still revealed the (S/T)Q motif for ETO indicating more elevated phosphorylation of substrates of Atm/Atr/Prkdc after ETO than CDDP (Fig. 4).

Activation of Atm kinase, as indicated by autophosphorylation of S1987 (Fig. 5a), was induced by ETO, to a lesser extent by CDDP and CsA and virtually not by DEM. Interestingly, phosphorylation of Chek1 at S317, a unique activation marker for the Atr kinase, occurred at similar levels after CDDP and ETO treatment, but hardly after exposure to CsA and not after DEM. Unfortunately, the autophosphorylation site of the third DDR-associated kinase Prkdc, pS2053, was not detected in our MS experiment and remains undetected by any global MS-based study as evident from the PhosphositePlus database (Hornbeck et al. 2012). Moreover, no unique substrate for the activated $P r k d c$ has been identified posing limitations to the interpretation of its involvement in the DDR. Consistent with the relative levels of Atm and Atr activation, (S/T)Q site phosphorylation of Rad50 (S237, S635) and Nbn (S58, S343) components of the DSB-recognition complex MRN was most pronounced after ETO exposure (Fig. 5b), while Brcal and Brca2, required for replication fork protection (Schlacher et al. 2012), were equally phosphorylated upon CDDP and ETO exposure but hardly after CsA and not after DEM. The activation of Atr requires its interaction with the Atr-activator Topbpl, which contains an ATR-activation domain that stimulates ATR kinase activity (Duursma et al. 2013). Indeed, we observed distinct phosphorylation of Topbpl (S/T)Q sites (pS1140, pS1273 and pS1380) after ETO and CDDP with higher amplitudes after ETO compared to CDDP (Fig. 5b). The abovementioned phosphorylation of components of the DSB-recognition complex MRN by Atm activates Atr via Topbpl recruitment (Duursma et al. 2013; Yoo et al. 2009; Kumagai et al. 2006) leading to Chekl activation. In contrast, phosphorylation of Topbpl is hardly manifest after CsA and absent after DEM. (Fig. 5b). Western blot analysis confirmed divergent activation of the DDR by the four stressors. Equitoxic doses of CDDP and ETO resulted in a time-dependent increase of the DSB markers $\gamma$-H2AX and pS1987 Atm, as well as pS15 Tp53 (indicative of cell cycle arrest and apoptosis) (Supplementary Fig. S7).

In contrast, mES cells exposed to CsA displayed activation of these key nodes of the DDR only after extended exposure time $(25 \mathrm{~h})$, while no evidence for the induction of the DDR was observed for DEM. Both ETO and CsA showed, besides enrichment of the (S/T)Q motif, enrichment for an acidic residue at +3 position suggesting activation of the CK2 kinase by ETO and CsA (Son et al. 
A

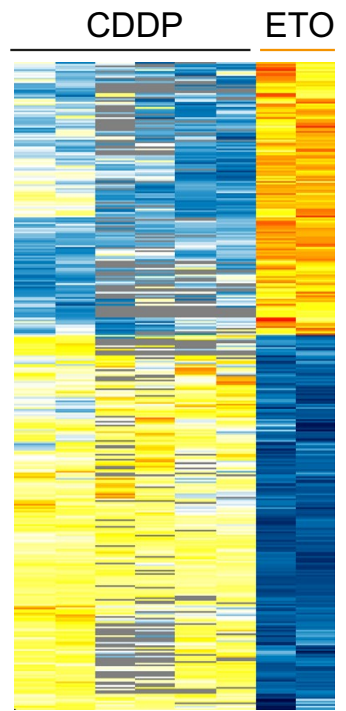

2,027 phosphosites

T-test FDR $<0.05$

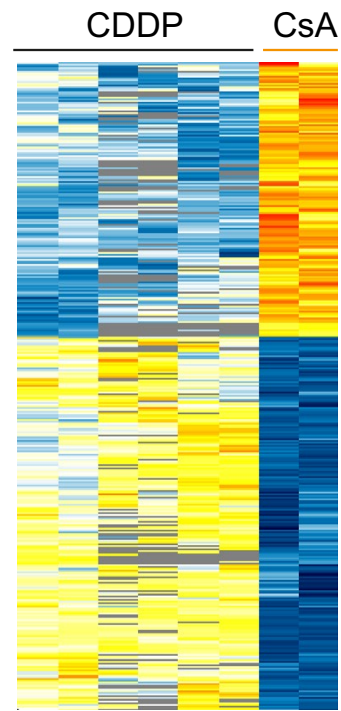

1,590 phosphosites

T-test FDR <0.05

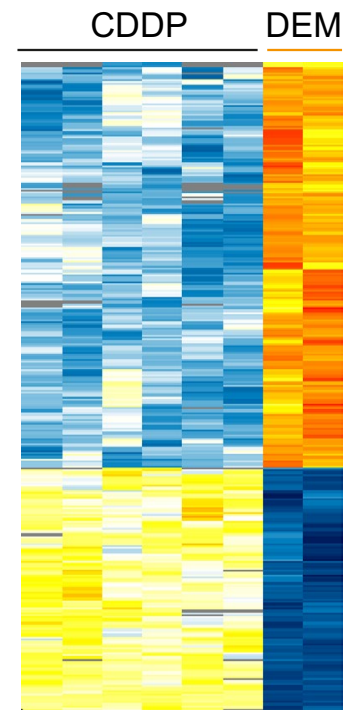

292 phosphosites

T-test FDR $<0.05$

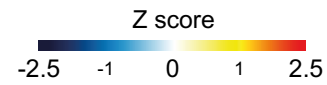

Up cluster

Down cluster

B

Up cluster

Down cluster

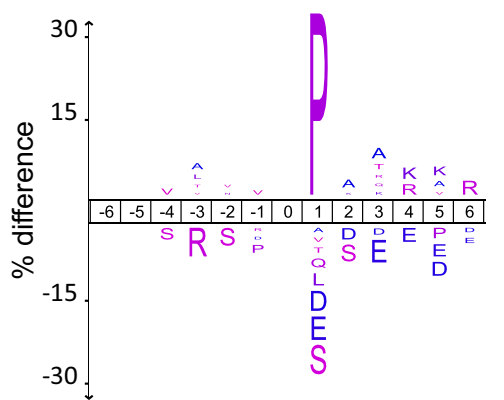

ETO

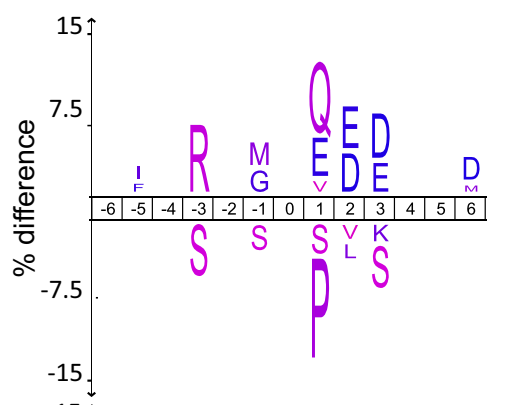<smiles>F[131I][131I]</smiles>

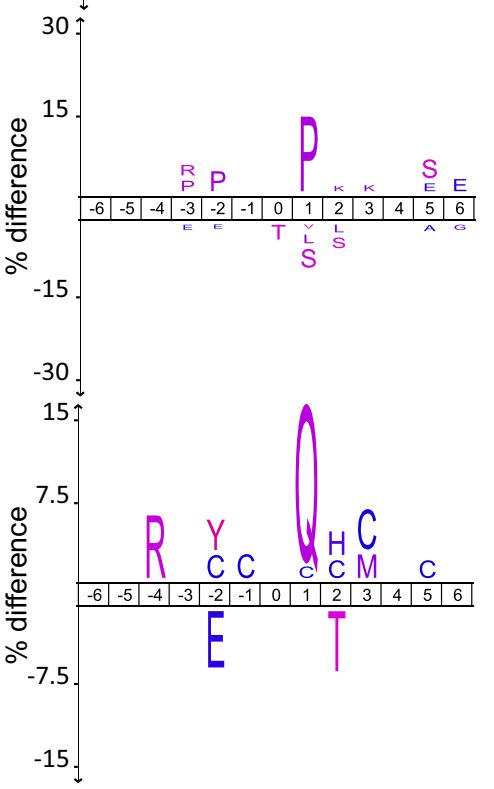


4Fig. 4 Comparative analysis of the phosphorylation response after ETO, CsA and DEM exposure to the response observed after CDDP treatment. a Heatmap of phosphosites that-for the indicated stressors-significantly differed in their regulation compared to CDDP. Clusters with phosphosites that responded more strongly or more weakly compared to CDDP are marked as "up cluster" and "down cluster", respectively. b Motifs enriched for the indicated stressors in "up cluster" (left panel) and "down cluster" (right panel). The sequences of total quantified phosphosites for ETO, CsA or DEM were used as background for the respective cluster. A $p$-value cut-off of 0.05 was applied

2013). Consistently, phosphorylation of several putative substrates of CK2 kinase (Rusin et al. 2017) including Dkcl pS453 and Hdacl pS423 was enhanced after CsA and ETO (Supplementary Fig. S8). Motif enrichment analysis on the down-regulated phosphosites (Fig. 3b) disclosed a clear enrichment for threonine following treatment with CDDP, ETO or CsA. Threonine-based dephosphorylation is an important mechanism for cell cycle checkpoint activation (Godfrey et al. 2017). Furthermore, enrichment of proline $(\mathrm{P})$ flanking the phosphorylated residue in response to ETO and a lesser extent in response to CsA suggests the inhibition of proline-directed kinases, whereas the enrichment of hydrophobic amino acids leucine (L) and phenylalanine (F) in response to CDDP and a lesser extent after CsA is congruent with diminished Pololike kinase-mediated phosphorylation (Kettenbach et al. 2012; Nakajima et al. 2003; Cundell et al. 2016; McCloy et al. 2015; Hein et al. 2017; Malik et al. 2009).

Since three of the four stressors prominently induced the activation of Atm and/or Atr kinases, we wondered whether and to what extent these kinases were involved in the prevention of stressor-induced cell death. To this end, we treated mES cells with the four stressors in the presence and absence of either an Atm- or an Atr-inhibitor and determined the fraction of apoptotic/necrotic cells. In the absence of kinase inhibitors, apoptosis was induced by CDDP and ETO and to a lesser extent by CsA but not by DEM. While Atm inhibition slightly affected apoptosis after CDDP and CsA (Fig. 5c), inhibition of Atr lead to an enhanced apoptotic response upon exposure to CDDP or ETO, but not after CsA or DEM, correlating well with the observed extent of Atr-mediated phosphorylation of the S317 residue in Chek1 (Walker et al. 2009). Congruent with the observed extent of replication inhibition (Fig. 1b), these results indicate that the induction of programmed cell death in rapidly proliferating mES cells is predominantly driven by the interference of these stressors with DNA replication.

\section{Pathway analysis}

To identify stressor-activated pathways, we extracted the phosphosites that responded to at least one of the four stressors utilizing a combination of threshold filtering and statistical testing. As specified above, the application of a threshold filter of 1.5FC provided us with 6386 responsive phosphosites, while statistical testing (ANOVA test, FDR $<0.05$ ) revealed 3220 phosphosites that responded differentially to all four stressors. Taken together, a total of 7883 stressorresponsive phosphosites was identified out of which 2177 phosphosites are novel sites that have not yet been reported in the PhosphoSitePlus database (October 2019) (Hornbeck et al. 2012). The 7883 stressor-responsive phosphosites were subjected to ingenuity pathway analysis (IPA) to dissect pathways regulated by the four stressors (Fig. 6a). ETO and CDDP share a strong activation of DDR manifested by the significant enrichment of the Atm, Chekl/2, Brcalrelated DNA damage signaling, cell cycle checkpoints, and repair pathways. More specifically, ETO-activated pathways included IL-8, 14-3-3 and MAPK-mediated signaling. Only in case of ETO enrichment of upstream kinases, i.e. Atm, Atr, Prkdc (DNA-PKcs), the DDR-related Stk11 (also known as LKB1) and its activator Strada (Fig. 6b) as well as phosphatase $P p p 2 c b$ (a beta isoform of the catalytic subunit of the PP2A) was statistically significant. CDDP treatment significantly upregulated phosphatase Ppp2r2a (also known as B55A), death-associated protein kinase Dapkl as well as Mapkl/2 kinases that are stimulated upon extra- and intracellular signals. Exclusive to CsA is the down-regulation of various signaling pathways (Granzyme B, ErbB2, NGF, Rho GTPase, AML) that are among others involved in the regulation of cell cycle, apoptosis and extracellular matrix degradation (Mishra et al. 2018). Moreover, these pathways are known to be linked to kinases (i.e. MAPK, ERK, CDK) specifically down-regulated after treatment with CsA. Interestingly, activation of the Atm signaling pathway was also manifest in CsA-exposed mES cells. DEM exposure significantly activated a wide array of signaling pathways (e.g. Phospholipase C, B-cell activating factor) with upregulation of the nutrient and stress-responsive PAS domaincontaining serine/threonine-protein kinase (Pask) and the redox-sensitive serine/threonine-dependent phosphatase calcineurin. DEM hardly affected DDR pathways and upstream kinases/phosphatases. On the contrary, DEM was the only stressor that significantly down-regulated pathways controlling mitotic exit (Polo-like kinase-related networks) as well as self-renewal and differentiation (Oct4 related networks), yet no significant changes in upstream kinases $P l k l$ or $C d k l$ (regulator of Oct4) (Kim et al. 2018) were manifest. Despite this lack of significance from the upstream analysis of IPA, the down-regulated phosphosites that responded to all stressors (Fig. 2b), included pT210 Plkl as the only known 
A
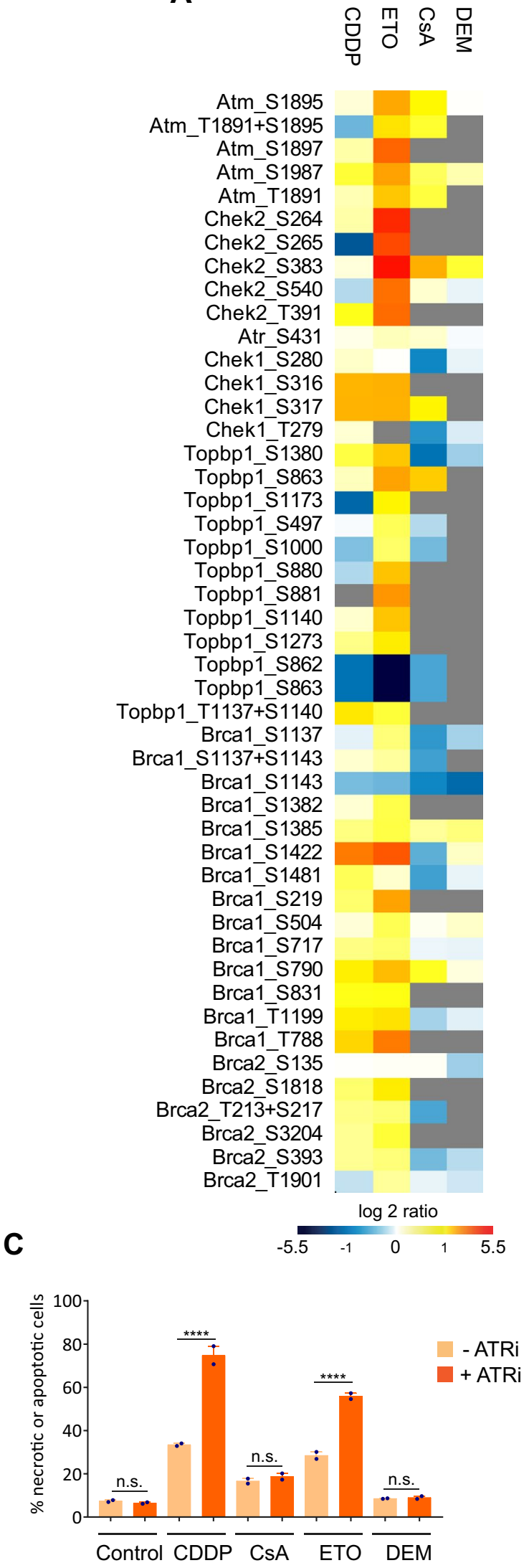

B

(S/T)Q sites

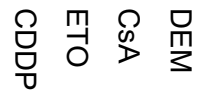
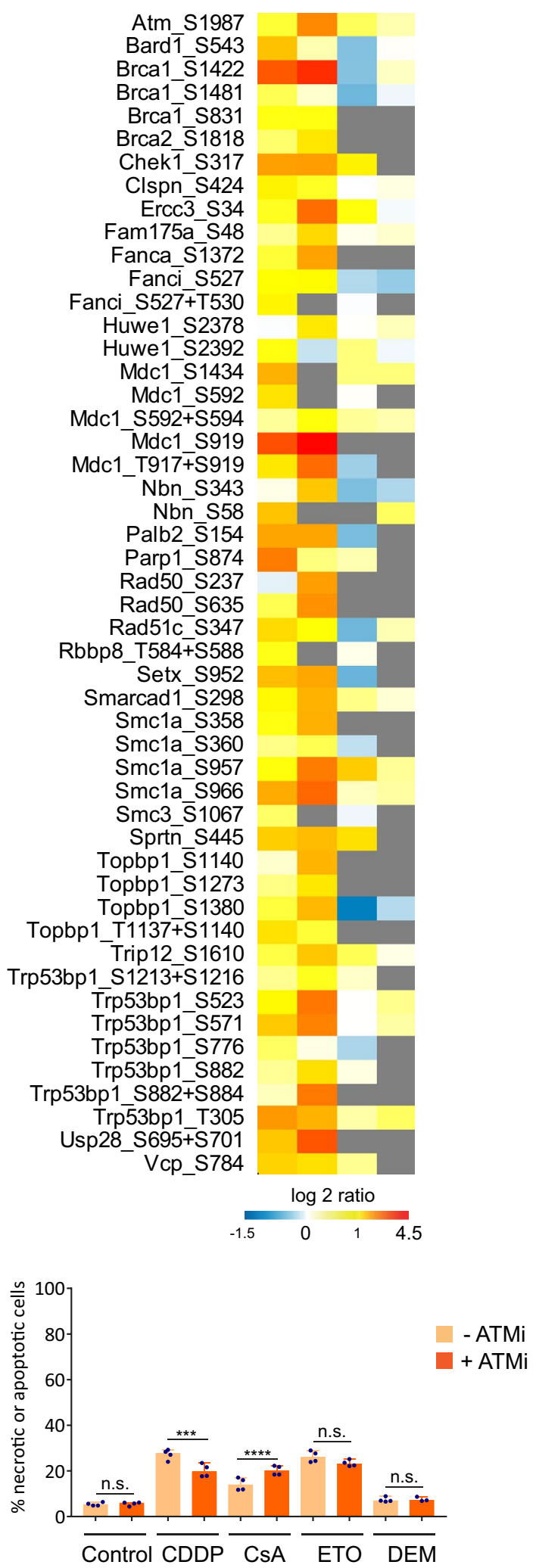
4Fig. 5 Differential phosphorylation responses of DNA damage response-related proteins. a Heatmap of the level of differential phosphorylation at various sites within the DDR-related proteins: Atm, Chek2, Atr, Chek1, Topbp1, Brca1, and Brca2. b Heatmap of the level of phosphorylation for 50 phosphosites with an $(\mathrm{S} / \mathrm{T}) \mathrm{Q}$ motif in proteins selected using "DDR" in the "Keywords" annotation from UniProt. c Fraction of apoptotic/necrotic cells as determined by Annexin $\mathrm{V}$ staining at $24 \mathrm{~h}$ after initiation of stressor exposure in the presence or absence of indicated kinase inhibitors. Statistics: one-way ANOVA test between cells treated with indicated stressors with or without the indicated inhibitors $(* * * * p$-value $<0.001$; $* * * p$-value $=0.0006 ; n$.s. not significant)

regulatory phosphosite. Dephosphorylation of this site leads to the inactivation of $P l k l$ and consequently cell cycle arrest (Bruinsma et al. 2017). ETO, CDDP, and CsA shared significant down-regulation of $G s k 3$ and $C a m k 2 d$ kinases, whereas the DEM-mediated change appeared to be not significant. Gsk3 and Camk2d kinases act as negative regulators of the Wnt pathway (Patel and Woodgett 2017; Carreras Puigvert et al. 2013; Cong et al. 2014). Consistently, only DEM significantly upregulated the Wnt pathway.

\section{Discussion}

Here, we present a global phosphoproteome analysis of $\mathrm{mES}$ cells exposed to equitoxic doses (50\% cell viability) of four stressors with distinct modes of action that do not require bioactivation. Over 7883 stressor-responsive phosphosites were identified. The four stressors elicit cellular responses through distinctive and complex phosphorylation signaling cascades involving different kinases and phosphatases. However, the global activation of the kinases (and phosphatases), as well as functional interpretation of the phosphoproteome dataset is vastly restricted by the small proportion of reported phosphosites $(\sim 2 \%)$ that have been assigned to a regulatory kinase and another small proportion $(\sim 3 \%)$ that have a reported biological function. The fact that many of these phosphosites are substrates of more than one kinase further complicates data interpretation (Needham et al. 2019). While ETO ( 28\%) and CsA ( 24\%) displayed strong global phosphoproteome changes based on threshold filtering, CDDP $(\sim 12 \%)$ and DEM $(\sim 7 \%)$ displayed moderate and weak phosphoproteome changes, respectively. Motif and pathway analyses did not reveal any common motifs and pathways for all four stressors.

Analysis of the up-regulated phosphosites showed that ETO exposure led to activation of Atm as well as Atr as evident from extensive phosphorylation of their downstream effectors Chek2 (5 sites) and Chekl (2 sites), respectively. In contrast, after CDDP, only Atm S1987 was significantly phosphorylated. CDDP-mediated phosphorylation of Atrdependent Chekl (2 sites) was qualitatively and quantitatively similar to ETO. The picture that emerges is that both
DNA damage-inducing agents generate replication-blocking lesions leading to similar levels of Atr activation, whereas the differential activation of Atm appears to reflect differences in the rate at which DSBs are being generated by ETO and CDDP or possibly their nature. ETO can induce replication-independent DSB resulting from the collision of the transcription machinery with trapped topoisomerase II, while replication-blocking lesions induced by either ETO or CDDP will predominantly give rise to DSBs during the (next) S-phase and thus appear at later time points than $4 \mathrm{~h}$ after initiation of treatment. Indeed, Atm auto-phosphorylation at $\mathrm{S} 1987$ as determined by western blot analysis displayed more rapid kinetics after ETO than CDDP exposure (Supplementary Fig. S7). In line with the phosphorylation data indicating activation of cell cycle checkpoints related to replication stress, treatment with ETO and CDDP-induced time-dependent inhibition of DNA synthesis as well as apoptosis as reported previously (Lehman et al. 2017; Brozovic et al. 2009; Tammaro et al. 2013; Wu et al. 2011). The apoptotic response in mouse ES cells appears to be predominantly driven by replication stress as inhibition of Atr but not Atm enhanced the induction of apoptosis. Pathway analysis also indicated a strong regulation of several DDR-related pathways after ETO and/or CDDP including mitogen-activated protein kinase (MAPK), CHEK and BRCA1-mediated pathways.

The CsA phosphoproteome also showed enrichment of the (S/T)Q motif but with a prominent enrichment for an acidic residue at +3 position indicative of enhanced CK2 activity (Bian et al. 2013). CsA-associated phosphorylation of Atm (four sites including S1987 and T1891), Chek1 (one site) and Chek2 (one site) coincide with a decrease in DNA synthesis albeit significantly delayed when compared to ETO and CDDP. Different from ETO and CDDP, the apoptotic response after CsA appeared not to be affected by Atr inhibition. Whereas western blot analysis could not demonstrate active Atm signaling at $4 \mathrm{~h}$ after CsA, a moderate increase of y-H2AX and pS1987 Atm levels was observed after $24 \mathrm{~h}$ exposure suggestive of the induction of DSBs. It is tempting to speculate that the observed inhibition of DNA synthesis and apoptosis induction is related to a delayed generation of DSBs by CsA treatment. Indeed, exposure of primary human skin fibroblasts to a low dose of CsA $(5 \mu \mathrm{M})$ during $24 \mathrm{~h}$ has been shown to induce Tp53bpl foci (indicative for DSBs). These breaks have been suggested to arise from SSB during DNA replication and were suggested to result from a general inability to repair DSBs (Zhang et al. 2006). Specific CsA responses at the phosphoproteome level include the down-regulation of pathways that control hematopoietic differentiation and immunity (Granzyme B, ErbB2, NGF, Rho GTPase, AML) being consistent with known effects of CsA as an immunosuppressant (Zhou et al. 2015) and inducer of apoptosis (Koppelstaetter et al. 2018). 
A

Canonical Pathways

B Upstream kinases/phosphatases

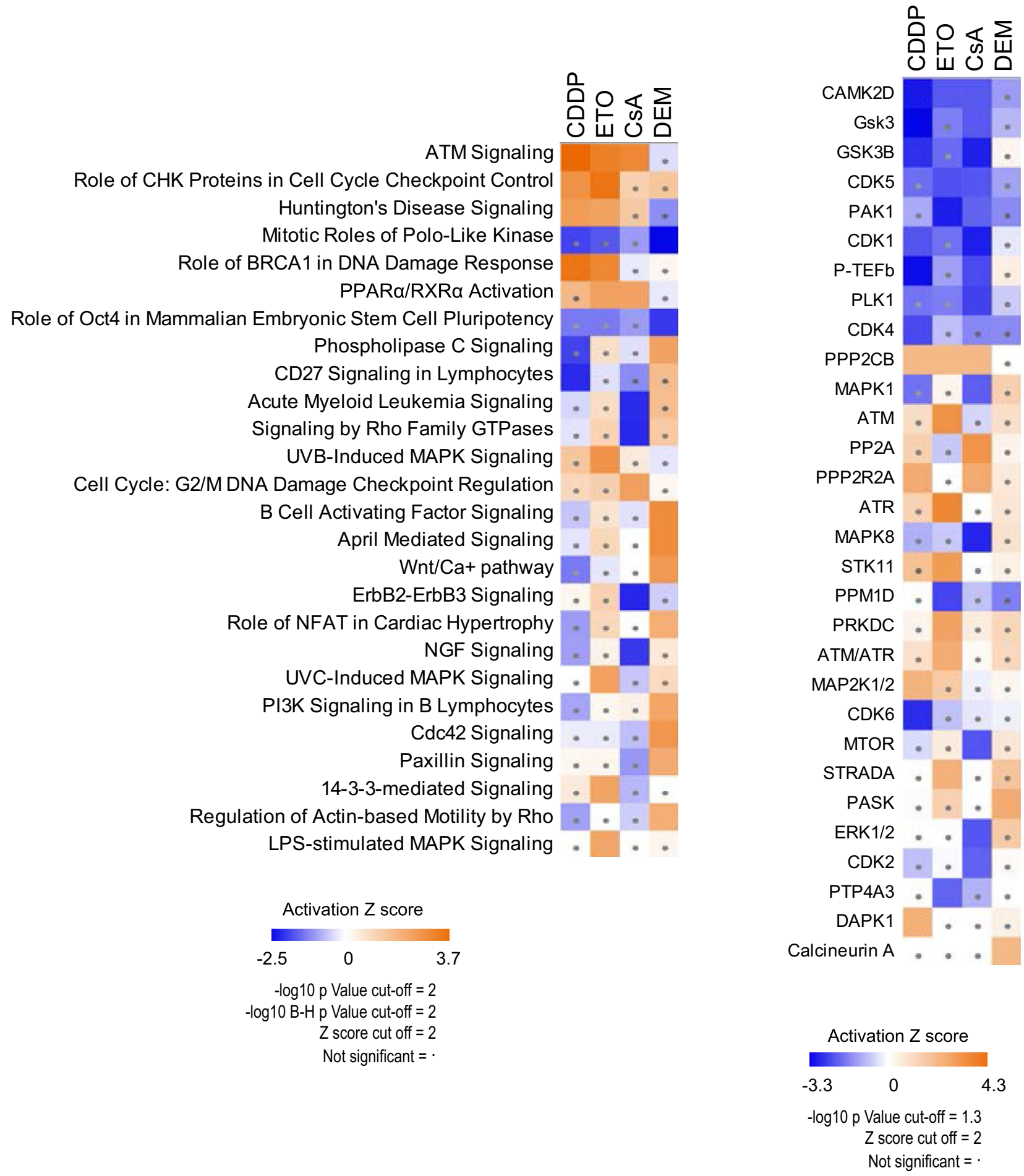

Fig. 6 Pathway analysis. a Heatmap of the activation $Z$ score (IPA) of statistically significantly enriched pathways for at least one of the stressors. Hierarchical clustering was used to group pathways as well as the stressors. Dots in the blocks indicate insignificant values $(z$ score $<2$ ). b Heatmap of the activation $Z$ score (IPA) of statisti- cally significantly enriched upstream kinases and phosphatases for at least one of the stressors. Hierarchical clustering was used to group the kinases/phosphatases as well as the stressors. Dots in the blocks indicate insignificant values $(z$ score $<2)$ 
We did not observe any indication that DNA damage signaling was activated after DEM, consistent with reports that the induction of the DNA damage response by DEM is only observed after high concentrations (Hiemstra et al. 2017). Rather, DEM-associated stress pathways appear to be linked to processes responding to enhanced levels of oxidative stress in line with its accepted mode of action as pro-oxidant. One of the pathways activated after DEM exposure concerns the induction of Pask and the redox-sensitive serine/threonine-dependent phosphatase calcineurin. Pask is a regulator of intracellular signaling pathways responding to both extrinsic and intrinsic stimuli and is important for the proper regulation of glucose metabolism and oxidative stress in mammals (Huang et al. 2014).

Among down-regulated phosphosites, a clear enrichment for threonine was observed after exposure to CDDP, ETO, and CsA, but not to DEM. This observation correlates well with the observed levels of DNA replication inhibition as threonine-based phosphorylation signaling is especially associated with cell cycle progression and its dephosphorylation is an important mechanism for cell cycle checkpoint activation (Godfrey et al. 2017). Dephosphorylation of threonine could be mediated by phosphatases targeting sites that are substrates of proline-or hydrophobic residue-directed kinases consistent with the overrepresentation of proline (ETO and CsA) and leucine and phenylalanine (CDDP and CsA) in the downregulated phosphosites. The phosphatase Pp2A-B55 has been shown to inhibit proline-directed phosphorylation specifically against threonine/proline motifs conferring time resolution in cell cycle checkpoint activation and progression (McCloy et al. 2015; Hein et al. 2017). Motif analysis indicates that the checkpoint might be activated by Pp2A-related phosphatase activities notably Pp2A-B55. It has been shown that PP2A can induce apoptosis (Zhou et al. 2017) and counteract Atr-Chekl signaling (Leung-Pineda et al. 2006).

In summary, the DNA damaging agent CDDP, the topoisomerase inhibitor ETO, the immunosuppressive agent CsA and the pro-oxidant DEM elicit distinctive and complex phosphorylation signaling cascades at equitoxic doses. Phosphoproteome analyses revealed stressor-specific pathways and kinase motifs related to their cellular actions. This study demonstrates that phosphoproteomics analysis is a powerful tool to characterize and dissect the various signaling responses after exposure to different types of stress. The various types of stressors displayed substantial differences in their signaling responses even in the case of CDDP and ETO that both generate replication stress and induce apoptosis via DNA damage.
Funding This work was supported by the Netherlands Genomics Initiative (NOW; no. 050-060-510). The work carried out in this study was in part supported by the Novo Nordisk Foundation Center for Protein Research and the European Commission's 7th Framework Program (HEALTH-F7-2010-242129/SYBOSS).

\section{Compliance with ethical standards}

Conflict of interest None declared.

Open Access This article is licensed under a Creative Commons Attribution 4.0 International License, which permits use, sharing, adaptation, distribution and reproduction in any medium or format, as long as you give appropriate credit to the original author(s) and the source, provide a link to the Creative Commons licence, and indicate if changes were made. The images or other third party material in this article are included in the article's Creative Commons licence, unless indicated otherwise in a credit line to the material. If material is not included in the article's Creative Commons licence and your intended use is not permitted by statutory regulation or exceeds the permitted use, you will need to obtain permission directly from the copyright holder. To view a copy of this licence, visit http://creativecommons.org/licenses/by/4.0/.

\section{References}

Batth TS, Papetti M, Pfeiffer A, Tollenaere MAXA, Francavilla C, Olsen JV (2018) Large-scale phosphoproteomics reveals Shp-2 phosphatase-dependent regulators of Pdgf receptor signaling. Cell Rep 22:2784-2796

Bennetzen MV, Larsen DH, Bunkenborg J, Bartek J, Lukas J, Andersen JS (2010) Site-specific phosphorylation dynamics of the nuclear proteome during the DNA damage response. Mol Cell Proteom 9:1314-1323

Bian Y, Ye M, Wang C, Cheng K, Song C, Dong M, Pan Y, Qin H, Zou H (2013) Global screening of CK2 kinase substrates by an integrated phosphoproteomics workflow. Sci Rep 3:3460

Brozovic A, Damrot J, Tsaryk R, Helbig L, Nikolova T, Hartig C, Osmak M, Roos WP, Kaina B, Fritz G (2009) Cisplatin sensitivity is related to late DNA damage processing and checkpoint control rather than to the early DNA damage response. Mutat Res 670:32-41

Bruinsma W, Aprelia M, García-Santisteban I, Kool J, Xu YJ, Medema RH (2017) Inhibition of Polo-like kinase 1 during the DNA damage response is mediated through loss of Aurora A recruitment by Bora. Oncogene 36:1840-1848

Carreras Puigvert J, von Stechow L, Siddappa R, Pines A, Bahjat M, Haazen LC, Olsen JV, Vrieling H, Meerman JH, Mullenders LH et al (2013) Systems biology approach identifies the kinase Csnk1a1 as a regulator of the DNA damage response in embryonic stem cells. Sci Signal 6:ra5

Choudhary C, Mann M (2010) Decoding signalling networks by mass spectrometry-based proteomics. Nat Rev Mol Cell Biol 11:427-439

Colaert N, Helsens K, Martens L, Vandekerckhove J, Gevaert K (2009) Improved visualization of protein consensus sequences by iceLogo. Nat Methods 6:786-787

Cong W, Liu B, Liu S, Sun M, Liu H, Yang Y, Wang R, Xiao J (2014) Implications of the Wnt5a/CaMKII pathway in retinoic acidinduced myogenic tongue abnormalities of developing mice. Sci Rep 4:6082 
Cundell M, Hutter L, Bastos R, Poser E, Holder J, Mohammed S, Novak B, Barr F (2016) A PP2A-B55 recognition signal controls substrate dephosphorylation kinetics during mitotic exit. J Cell Biol 214:539-554

Deweese JE, Osheroff N (2009) The DNA cleavage reaction of topoisomerase II: wolf in sheep's clothing. Nucleic Acids Res 37:738-748

Duursma AM, Driscoll R, Elias JE, Cimprich KA (2013) A role for the MRN complex in ATR activation via TOPBP1 recruitment. Mol Cell 50:116-122

Francavilla C, Rigbolt KTG, Emdal KB, Carraro G, Vernet E, Bekker-Jensen DB, Streicher W, Wikström M, Sundström M, Bellusci $S$ et al (2013) Functional proteomics defines the molecular switch underlying FGF receptor trafficking and cellular outputs. Mol Cell 51:707-722

Godfrey M, Touati SA, Kataria M, Jones A, Snijders AP, Uhlmann F (2017) PP2ACdc55 phosphatase imposes ordered cell-cycle phosphorylation by opposing threonine phosphorylation. Mol Cell 65:393-402.e3

Hein JB, Hertz EPTP, Garvanska DH, Kruse T, Nilsson J (2017) Distinct kinetics of serine and threonine dephosphorylation are essential for mitosis. Nat Cell Biol 19:1433-1440

Hiemstra S, Niemeijer M, Koedoot E, Wink S, Klip JE, Vlasveld M, de Zeeuw E, van Os B, White A, van de Water B (2017) Comprehensive landscape of Nrf2 and p53 pathway activation dynamics by oxidative stress and DNA damage. Chem Res Toxicol 30:923-933

Hogrebe A, von Stechow L, Bekker-Jensen DB, Weinert BT, Kelstrup CD, Olsen JV (2018) Benchmarking common quantification strategies for large-scale phosphoproteomics. Nat Commun 9:1045

Hornbeck PV, Kornhauser JM, Tkachev S, Zhang B, Skrzypek E, Murray $\mathrm{B}$, Latham V, Sullivan $\mathrm{M}$ (2012) PhosphoSitePlus: a comprehensive resource for investigating the structure and function of experimentally determined post-translational modifications in man and mouse. Nucleic Acids Res 40:D261-D270

Huang M, Xu Q, Mitsui K, Xu Z (2014) PSK1 regulates expression of SOD1 involved in oxidative stress tolerance in yeast. FEMS Microbiol Lett 350:154-160

Humphrey SJ, Azimifar SB, Mann M (2015) High-throughput phosphoproteomics reveals in vivo insulin signaling dynamics. Nat Biotechnol 33:990-995

Humphrey SJ, Karayel O, James DE, Mann M (2018) High-throughput and high-sensitivity phosphoproteomics with the EasyPhos platform. Nat Protoc 13:1897-1916

Kettenbach AN, Wang T, Faherty BK, Madden DR, Knapp S, BaileyKellogg C, Gerber SA (2012) Rapid determination of multiple linear kinase substrate motifs by mass spectrometry. Chem Biol 19:608-618

Kim HJ, Shin J, Lee S, Kim TW, Jang H, Suh MY, Kim J-HH, Hwang I-YY, Hwang DS, Cho E-JJ et al (2018) Cyclin-dependent kinase 1 activity coordinates the chromatin associated state of Oct4 during cell cycle in embryonic stem cells. Nucleic Acids Res 46:6544-6560

Koppelstaetter C, Kern G, Leierer G, Mair SM, Mayer G, Leierer J (2018) Effect of cyclosporine, tacrolimus and sirolimus on cellular senescence in renal epithelial cells. Toxicol In Vitro 48:86-92

Kumagai A, Lee J, Yoo H, Dunphy W (2006) TopBP1 activates the ATR-ATRIP complex. Cell 124:943-955

Lehman CE, Dillon LW, Nikiforov YE, Wang Y-HH (2017) DNA fragile site breakage as a measure of chemical exposure and predictor of individual susceptibility to form oncogenic rearrangements. Carcinogenesis 38:293-301

Leung-Pineda V, Ryan C, Piwnica-Worms H (2006) Phosphorylation of Chk1 by ATR is antagonized by a Chk1-regulated protein phosphatase 2A circuit. Mol Cell Biol 26:7529-7538
Leyking S, Budich K, van Bentum K, Thijssen S, Abdul-Khaliq H, Fliser D, Sester M, Sester U (2015) Calcineurin inhibitors differentially alter the circadian rhythm of T-cell functionality in transplant recipients. J Transl Med 13:51

Malik R, Lenobel R, Santamaria A, Ries A, Nigg E, Körner R (2009) Quantitative analysis of the human spindle phosphoproteome at distinct mitotic stages. J Proteome Res 8:4553-4563

Matsuda S, Koyasu S (2000) Mechanisms of action of cyclosporine. Immunopharmacology 47:119-125

Mazouzi A, Stukalov A, Müller ACC, Chen D, Wiedner M, Prochazkova J, Chiang S-CC, Schuster M, Breitwieser FP, Pichlmair A et al (2016) A Comprehensive analysis of the dynamic response to aphidicolin-mediated replication stress uncovers targets for ATM and ATMIN. Cell Rep 15:893-908

McCloy R, Parker B, Rogers S, Chaudhuri R, Gayevskiy V, Hoffman N, Ali N, Watkins N, Daly R, James D et al (2015) Global phosphoproteomic mapping of early mitotic exit in human cells identifies novel substrate dephosphorylation motifs. Mol Cell Proteom 14:2194-2212

Mishra R, Patel H, Alanazi S, Yuan L, Garrett JT (2018) HER3 signaling and targeted therapy in cancer. Oncol Rev 12:355

Nakajima H, Toyoshima-Morimoto F, Taniguchi E, Nishida E (2003) Identification of a consensus motif for Plk (polo-like kinase) phosphorylation reveals Myt1 as a Plk1 substrate. J Biol Chem 278:25277-25280

Needham EJ, Parker BL, Burykin T, James DE, Humphrey SJ (2019) Illuminating the dark phosphoproteome. Sci Signal 12:eaau8645

Olsen JV, Vermeulen M, Santamaria A, Kumar C, Miller ML, Jensen LJ, Gnad F, Cox J, Jensen TS, Nigg EA et al (2010) Quantitative phosphoproteomics reveals widespread full phosphorylation site occupancy during mitosis. Sci Signal 3:ra3

Olshan AF, Mattison DR, Zwanenburg TS (1994) International Commission for Protection Against Environmental Mutagens and Carcinogens. Cyclosporine A: review of genotoxicity and potential for adverse human reproductive and developmental effects. Report of a Working Group on the genotoxicity of cyclosporine A, August 18, 1993. Mutat Res 317:163-173

Patel P, Woodgett JR (2017) Glycogen synthase kinase 3: a kinase for all pathways? Curr Top Dev Biol 123:277-302

Piersma SR, Knol JC, de Reus I, Labots M, Sampadi BK, Pham TV, Ishihama Y, Verheul HM, Jimenez CR (2015) Feasibility of labelfree phosphoproteomics and application to base-line signaling of colorectal cancer cell lines. J Proteom 127:247-258

Pines A, Kelstrup CD, Vrouwe MG, Puigvert JC, Typas D, Misovic B, de Groot A, von Stechow L, van de Water B, Danen EH et al (2011) Global phosphoproteome profiling reveals unanticipated networks responsive to cisplatin treatment of embryonic stem cells. Mol Cell Biol 31:4964-4977

Polo SE, Jackson SP (2011) Dynamics of DNA damage response proteins at DNA breaks: a focus on protein modifications. Genes Dev 25:409-433

Purvis JE, Lahav G (2013) Encoding and decoding cellular information through signaling dynamics. Cell 152:945-956

Rusin S, Adamo M, Kettenbach A (2017) Identification of candidate casein kinase 2 substrates in mitosis by quantitative phosphoproteomics. Front Cell Dev Biol 5:97

Schlacher K, Wu H, Jasin M (2012) A distinct replication fork protection pathway connects Fanconi anemia tumor suppressors to RAD51-BRCA1/2. Cancer Cell 22:106-116

Sharma K, D'Souza RC, Tyanova S, Schaab C, Wiśniewski JR, Cox J, Mann M (2014) Ultradeep human phosphoproteome reveals a distinct regulatory nature of Tyr and Ser/Thr-based signaling. Cell Rep 8:1583-1594

Son YK, Lee SM, An WS, Kim KH, Rha SH, Rho JH, Kim SE (2013) The role of protein kinase CK2 in cyclosporine-induced nephropathy in rats. Transplant Proc 45:756-762 
Tammaro M, Barr P, Ricci B, Yan H (2013) Replication-dependent and transcription-dependent mechanisms of DNA double-strand break induction by the topoisomerase 2-targeting drug etoposide. PLOS ONE 8:e79202

Tirmenstein MA, Nicholls-Grzemski FA, Zhang JG, Fariss MW (2000) Glutathione depletion and the production of reactive oxygen species in isolated hepatocyte suspensions. Chem Biol Interact 127:201-217

Todd RC, Lippard SJ (2009) Inhibition of transcription by platinum antitumor compounds. Metallomics 1:280-291

Tyanova S, Temu T, Cox J (2016a) The MaxQuant computational platform for mass spectrometry-based shotgun proteomics. Nat Protoc 11:2301-3231

Tyanova S, Temu T, Sinitcyn P, Carlson A, Hein MY, Geiger T, Mann M, Cox J (2016b) The Perseus computational platform for comprehensive analysis of (prote)omics data. Nat Methods 13:731-740

Van Kesteren PC, Beems RB, Luijten M, Robinson J, de Vries A, van Steeg H (2009) DNA repair-deficient Xpa/p53 knockout mice are sensitive to the non-genotoxic carcinogen cyclosporine A: escape of initiated cells from immunosurveillance? Carcinogenesis 30:538-543

Vesela E, Chroma K, Turi Z, Mistrik M (2017) Common chemical inductors of replication stress: focus on cell-based studies. Biomolecules 7:19

Walker M, Black EJ, Oehler V, Gillespie DA, Scott MT (2009) Chk1 C-terminal regulatory phosphorylation mediates checkpoint activation by de-repression of Chk1 catalytic activity. Oncogene 28:2314-2323

Wang D, Lippard SJ (2005) Cellular processing of platinum anticancer drugs. Nat Rev Drug Discov 4:307-320
Warmoes M, Jaspers JE, Xu G, Sampadi BK, Pham TV, Knol JC, Piersma SR, Boven E, Jonkers J, Rottenberg S et al (2013) Proteomics of genetically engineered mouse mammary tumors identifies fatty acid metabolism members as potential predictive markers for cisplatin resistance. Mol Cell Proteom 12:1319-1334

Weber CA, Duncan CA, Lyons MJ, Jenkinson SG (1990) Depletion of tissue glutathione with diethyl maleate enhances hyperbaric oxygen toxicity. Am J Physiol 258:L308-L312

Wu C-CC, Li T-KK, Farh L, Lin L-YY, Lin T-SS, Yu Y-JJ, Yen T-JJ, Chiang C-WW, Chan N-LL (2011) Structural basis of type II topoisomerase inhibition by the anticancer drug etoposide. Science 333:459-462

Yoo HY, Kumagai A, Shevchenko A, Shevchenko A, Dunphy WG (2009) The Mre11-Rad50-Nbs1 complex mediates activation of TopBP1 by ATM. Mol Biol Cell 20:2351-2360

Zhang A, Lyu YL, Lin C-PP, Zhou N, Azarova AM, Wood LM, Liu LF (2006) A protease pathway for the repair of topoisomerase IIDNA covalent complexes. J Biol Chem 281:35997-36003

Zhou X, Workeneh B, Hu Z, Li R (2015) Effect of immunosuppression on the human mesangial cell cycle. Mol Med Rep 11:910-916

Zhou H, Luo W, Zeng C, Zhang Y, Wang L, Yao W, Nie C (2017) PP2A mediates apoptosis or autophagic cell death in multiple myeloma cell lines. Oncotarget 8:80770-80789

Publisher's Note Springer Nature remains neutral with regard to jurisdictional claims in published maps and institutional affiliations.

\section{Affiliations}

\section{Bharath Sampadi ${ }^{1}$ Alex Pines ${ }^{1} \cdot$ Stephanie Munk ${ }^{2} \cdot$ Branislav Mišovic $^{1} \cdot$ Anton J. de Groot $^{1} \cdot$ Bob van de Water $^{3}$. Jesper V. Olsen ${ }^{2}$. Leon H. F. Mullenders ${ }^{1,4} \cdot$ Harry Vrieling ${ }^{1}$ (D)}

1 Department of Human Genetics, Leiden University Medical Center, P.O. Box 9600, 2300 RC Leiden, The Netherlands

2 Novo Nordisk Foundation Center for Protein Research, Proteomics Program, Faculty of Health and Medical Sciences, University of Copenhagen, Blegdamsvej 3b, 2200 Copenhagen, Denmark
3 Division of Drug Discovery and Safety, Leiden Academic Centre for Drug Research, Leiden University, Einsteinweg 55, 2333 CC Leiden, The Netherlands

4 Department of Genetics, Research Institute of Environmental Medicine (RIeM), Nagoya University, Nagoya, Japan 